\title{
Letramento em foco: os usos da escrita em uma comunidade escolar em Florianópolis (SC)
}

\author{
Focus on literacy: the uses of writing in a \\ community school in Florianópolis (SC)
}

\author{
Michelle Donizeth Euzébio* \\ Universidade Federal de Santa Catarina \\ Florianópolis - Santa Catarina / Brasil
}

\begin{abstract}
RESUMO: Este artigo topicaliza os usos sociais da escrita, ancorando-se nas teorizações dos estudos do letramento. Seu objetivo é descrever práticas e eventos de letramento vivenciados por um grupo de crianças residentes em um bairro de vulnerabilidade social, identificando concepções sobre a escrita na escola e depreendendo implicações de aprendizagem, no que diz respeito à formação dos alunos, decorrentes de similaridades ou diferenças entre tais práticas. Os resultados sugerem que haja uma flagrante ausência de escrita na ambientação escolar e nas aulas dessa classe, muitas vezes motivada pelas condições de a(na)lfabetismo dos alunos e, possivelmente, na origem, por uma tácita naturalização da não aprendizagem que tende a caracterizar espaços de vulnerabilidade social como esse.
\end{abstract}

PALAVRAS-CHAVE: modelos autônomo e ideológico de letramento, práticas e eventos de letramento.

\begin{abstract}
This study focuses the social uses of writing, based on the literacy studies. The objective of this paper is to describe practices and events of literacy experienced by a group of children who lives in a socially vulnerable neighborhood, identifying conceptions about writing in school and deducing learning implications, in what respects to the students formation, deriving from similarities or differences between these practices. The results suggests that there is a flagrant absence of writing in the scholar space and in the classes of this group, sometimes motivated by the conditions of some student's (il)literacy, and, possibly, in the beginning, by a tacit naturalization of the no learning that tends to characterize spaces of socially vulnerable as this one.
\end{abstract}

KEYWORDS: autonomous and ideological models of literacy, literacy practices and events.

\footnotetext{
*michelledoni@yahoo.com.br
} 


\section{Introdução}

Ao conceber as práticas de letramento como formas gerais de cultura, compreendemos que tais práticas constituem vivências que ancoram os usos da escrita, por meio das quais os indivíduos interagem durante suas vidas. Sob essa perspectiva, o conceito de letramento e suas implicaçôes requerem da escola sensibilidade à configuração das comunidades de prática (WENGER, 1998) em que os sujeitos se encontram inseridos, de modo que haja uma desconstrução do padrão cultivado nas instituiçōes de prestígio, sobretudo nas instituiçōes escolares, padrão este ligado à promoçăo social dos sujeitos, o que remete às teorizaçōes do modelo autônomo de letramento (STREET, 1984, 2003a).

Com base nessas considerações, este artigo focaliza a/o possível proximidade/afastamento entre a escola e a comunidade, os eventos de letramento no cotidiano escolar e as açōes docentes na ressignificação (ou não) das práticas de letramento dos alunos inseridos em uma escola localizada em um bairro de desprivilegiamento socioeconômico na cidade de Florianópolis (SC). As teorizaçôes que ancoram a discussão partem de Barton (1994); Barton, Hamilton e Ivanic (2000); Hamilton (2000a; 2000b) e Street (1984, 2003a; 2003b), entre outros estudiosos que tratam do tema.

\section{Discussões sobre grafocentrismo e comunidades de prática}

Tomar a escrita sob a perspectiva dos usos sociais a que se presta consiste em conceber a língua, tanto na modalidade oral quanto escrita, como objeto social. Sob esse olhar, o fenômeno do letramento implica compreender os diferentes usos sociais da escrita não apenas no que tange às práticas de ensino da língua no espaço escolar, tal como tem sido empreendido historicamente, mas, também, no que diz respeito às práticas de usos sociais da escrita que têm lugar em outras instituiçōes, tais como família, igreja, trabalho, entre outros espaços presentes na vida social. Sob essa perspectiva, tal como propóem Barton, Hamilton e Ivanic (2000), os letramentos são situados espacial e temporalmente, assim como os sujeitos que interagem por meio da modalidade escrita.

De acordo com Rojo (2009), as mais recentes abordagens acerca desses estudos têm apontado para a forma heterogênea na qual as práticas sociais de leitura e escrita se apresentam, uma vez que as práticas de letramento são situadas socioculturalmente (BARTON; HAMILTON; IVANIC, 2000). De acordo com Street (2003b), esse posicionamento traz implicações para o reconhecimento dos múltiplos letramentos, que variam no tempo e no espaço, 
mas que são também contestados nas relaçóes de poder, o que, em nosso entendimento, aponta para a discussão da pluralidade: por que alguns letramentos são dominantes, enquanto outros são marginalizados? Que relações de natureza política, social, econômica e cultural estão implicadas em tais categorizações? Trata-se de uma discussão fecunda sobre empoderamento, de grande importância no tratamento da pluralidade e que remete às teorizaçóes de Street (1984; 2003a; 2003b) acerca do modelo ideológico de letramento. Para o autor, tal modelo parte da premissa de que as práticas de letramento estão sempre enraizadas em relações de poder.

Autores que adotam essa perspectiva de pluralização e suas implicações de empoderamento, como Barton e Hamilton (1998) e Hamilton (2000a), propõem, em seus estudos, os letramentos dominantes e os letramentos vernaculares ou locais; tais autores compreendem que os letramentos dominantes estão associados a organizações formais, tais como escola, igreja, local de trabalho, comércio, nos quais estão previstos agentes. Já no que tange aos letramentos vernaculares, os autores compreendem que são essencialmente aqueles que identificamos como enraizados na experiência cotidiana e que servem aos propósitos de todos os dias.

Essa discussão remete aos estudos de Street (1984, 2003a, 2003b) e Street e Lefstein (2007) acerca dos pressupostos sobre a língua escrita, tais como modelos autônomo e ideológico de letramento. No entendimento de Brian Street, o modelo autônomo tem como implicação a escrita como tecnologia, tomada independentemente do contexto. Nessa concepção, as funções da linguagem são afetadas pelo domínio da escrita, principalmente no que diz respeito a funções lógicas. Desse modo, a oralidade seria secundária no que tange ao uso dessas funções, uma vez que a escrita seria a única possibilidade de habilitar os indivíduos no desenvolvimento de abstrações. Nessa perspectiva, há uma dicotomização entre a escrita e a oralidade, em que a primeira é regida pela racionalidade e pela lógica, ao passo que a segunda se refere a funçôes interpessoais da linguagem.

Em oposição ao modelo autônomo, Street (1984, 2003a, 2007) propõe o modelo ideológico de letramento, concepção a que se mostra adepto. Essa vertente pressupóe o letramento tomado como uma prática social, estando vinculado ao contexto social dos indivíduos. Por meio desse modelo, Street $(1984,2003 a, 2007)$ toma letramento em termos de práticas sociais concretas, sendo que, em seu entendimento, não deve haver dicotomização entre a comunicação oral e a escrita; o fenômeno do letramento deve ser visto na 
perspectiva do uso, e não da tecnologia, dado que a escrita é utilizada de maneira diferente entre as culturas, cada qual dessas duas modalidades da língua com suas finalidades específicas. Desse modo, sob a perspectiva de Street (1984, 2003a, 2007), o modelo ideológico foi criado não para negar o acesso à escolarização e aos bens culturais, direito de todo cidadão inserido em uma sociedade; a proposta do modelo ideológico consiste em entender a lógica dos usos sociais da escrita nas diferentes culturas, para, desse modo, contribuir com seu processo de formação e inserção na sociedade contemporânea.

Nesse percurso de discussões, vale retomar as teorizações de Barton (1994) - ancorado em estudos anteriores de Shirley Heath (2001) e Brian Street (1984) - no que se refere à caracterização e à distinção de/entre eventos e práticas de letramento. Barton e Hamilton (1998) e Barton (1994) compreendem que os eventos de letramento são as atividades em que o letramento tem um papel; geralmente há um texto (ou textos) escrito, central para a atividade, e pode haver conversa em torno dele. Eventos são episódios observáveis que surgem nas práticas e são moldados por elas. Segundo Barton (1994), a escrita desempenha diferentes funções na vida dos indivíduos, em múltiplas atividades nas quais essa modalidade da língua está presente; tratase dos eventos de letramento. Esse fenômeno consiste em ações de que a leitura e a escrita fazem parte.

Para os autores, as práticas de letramento, por sua vez, são as maneiras gerais com que cada cultura utiliza o letramento e nas quais as pessoas se baseiam quando participam de um evento de letramento. Na compreensão de Barton e Hamilton (2000, p. 7), no entanto, práticas não são unidades observáveis de comportamento, uma vez que envolvem também valores, atitudes, sentimentos e relaçōes sociais.

Devido à sua natureza situada, o letramento não é o mesmo em todos os contextos; para Barton e Hamilton $(1998,2000)$ existem letramentos diferentes com sentidos também diferentes. Sob esse entendimento, é legítimo reafirmar que dentro de certa cultura existem letramentos distintos associados a diferentes domínios da vida.

Entendemos que os sujeitos, já no ambiente familiar, carregam um conjunto de valores e estratégias frente ao reconhecimento das práticas educativas que, dependendo do entorno cultural, tende a ser concebido favorável ou desfavoravelmente. Em nossa compreensão, tal conjunto caracteriza a formação cultural dos indivíduos e, para as finalidades deste estudo, a valoração atribuída à escrita. 
No que respeita à escola, é imprescindível, nas práticas escolares, o envolvimento dos alunos em atividades cujos elementos constitutivos sejam trabalhos significativos, de modo que o engajamento dos estudantes nesse processo consista não apenas no cumprimento de aprendizagem de conteúdos determinados a priori, mas na construção de um interesse mútuo em torno de tais atividades. Sob essa perspectiva, a aprendizagem consiste em uma questão de pertencimento e de participação em que os membros interagem, aprendem conjuntamente e constroem relaçōes entre si, constituindo, desse modo, uma comunidade de prática. Tal conceito, elaborado por Wenger (1998), referencia um sistema no qual um grupo de pessoas compartilha interesses e objetivos comuns por meio de engajamento e interação em torno de atividades específicas. $\mathrm{O}$ autor compreende que as práticas de uma comunidade não existem na abstração, visto que só ganham "forma" na medida em que os indivíduos se engajam em ações cujo significado é negociado com todos os membros do grupo.

Acerca disso, vale referenciar Heath (2001), etnógrafa que realizou um estudo com crianças das comunidades estadunidenses de Maintown, Roadville e Trackton, relacionando práticas de letramento do cotidiano dessas crianças e as convergências ou não dessas práticas com o uso da escrita na escola. $O$ foco de pesquisa foi a contação de histórias a que os pais procedem ou não na hora em que os filhos vão dormir. Os resultados da análise de Heath (2001) sugerem que os usos sociais da escrita na comunidade de Maintown são muito semelhantes ao que acontece na escola; logo, as possibilidades de sucesso no processo de escolarização são maiores. Nas comunidades de Roadville e Trackton, no entanto, esses usos são bem distintos dos usos da escola, o que exigiria dessas crianças um esforço mais efetivo de apropriação dos usos da escrita tal qual acontecem na ambientação escolar.

Ao abordar essa discussão, Gee (2004) chama a atenção ao propor a ruptura da dicotomia existente entre processos culturais e processos de instrução com respeito à modalidade escrita da língua. Para o autor, a escrita precisa ser vista como um processo cultural, uma vez que não é, como a fala, uma propriedade da espécie, tampouco produto da artificialidade do ensino. Gee (2004) advoga em favor da hipótese de que o processo respectivo à leitura é um processo cultural, que se constrói nos meandros da cultura humana. Crianças que aprendem leitura como um processo cultural tendem a ter mais sucesso no percurso de escolarização, ao passo que crianças que aprendem a ler como processo instrucional na escola parecem ficar em desvantagem. 
No que se refere do fenômeno do letramento no espaço escolar, cabe ressaltar aqui que, historicamente, a formação dos indivíduos inseridos em quaisquer sociedades tende a se delinear, entre outras possibilidades, em dois universos específicos: informalmente, na família ou em outros lugares sociais; ou formalmente, por meio de diferentes agências de letramento, sobretudo no que concerne às esferas escolar e acadêmica (BALTAR, 2010). No entendimento de Baltar (2010, p. 211), "No quadro da formação inicial e universitária, os humanos responsáveis pela formação dos outros humanos são denominados professores". Tais profissionais são tidos como os responsáveis pela promoção da aprendizagem, uma vez que se caracterizam por desenvolver nos alunos determinadas habilidades e competências provenientes da educação formal (OLIVEIRA, 2010), o que implica, ancorado no conceito de mediação semiótica de Vygotsky (1998), conceber o professor como protagonista na coconstrução dos saberes escolarizados.

Sobre isso, Kleiman $(2006,2007)$ argumenta que a representação usual do professor como mediador, à luz das teorizações de mediação semiótica de Vygotsky (1998), devido ao discurso do senso comum, perdeu os sentidos originais do conceito, sobretudo porque, atualmente, a sociedade " [...] passou a ver o mediador como aquele que está no meio, aquele que medeia, por exemplo, a interação entre autor e leitor, arbitrando sobre significados e interpretaçōes" (KLEIMAN, 2007, p. 414).

Apoiamos teorizações de Kleiman (2006) segundo as quais, uma vez que houve esse apagamento da dimensão semiótica do conceito original de professor como mediador, cabe, se não substituir, estabelecer um paralelo entre as concepções vygotskyanas e a concepção de professor como agente de letramento. Sob essa nova identidade, entendemos que é responsabilidade do docente inserir os alunos nas práticas de letramento que caracterizam os saberes escolares, de modo que promova uma hibridização entre as práticas de letramento dominantes e as práticas de letramento vernaculares (STREET, 2003a). Segundo Kleiman (2006, p. 83), "Um agente social é um mobilizador dos sistemas de conhecimento pertinentes, dos recursos, das capacidades dos membros da comunidade: no caso da escola". Para a autora, tal agente "[...] seria um promotor das capacidades e recursos de seus alunos e suas redes comunicativas para que participem das práticas sociais de letramento, as práticas de uso da escrita situadas, das diversas instituiçōes" (KLEIMAN, 2006, p. 83). Ainda de acordo com a estudiosa, por trazer subjacentes os usos da escrita como prática social, os estudos do letramento sugerem que a concepção do ensino da escrita delimita a ideia de intermediador concebido no senso comum, visto que todos os participantes inseridos na interação são tomados como mediadores. 
Desse modo, em nosso entendimento, conceber o professor como agente de letramento, tanto em substituição quanto em paralelo ao conceito de mediador, ancorado nas postulaçôes de Vygotsky (1998), implica conceber o espaço escolar como um local em que todos - professores, alunos, funcionários, familiares - compartilhem e construam conhecimento, de modo que, a partir da prática social em que todos estão inseridos, haja um compartilhamento de interesses do grupo como um todo, constituindo, assim, uma comunidade de prática (WENGER, 1998), em que todos os sujeitos se encontrem engajados em torno de um objetivo comum. Assim, assumir o professor como agente de letramento implica propor novos encaminhamentos para as atividades didáticopedagógicas por meio das quais ele empreende sua ação.

Ao refletir sobre as açôes didáticas no ambiente escolar, Halté (2008), com o objetivo de ressignificar as discussões acerca dessas mesmas açōes, empreende, em seus estudos, uma crítica ao conceito de transposição didática, que remete às teorizações de Chevallard (1985), sugerindo uma nova teorização acerca das práticas didáticas no espaço escolar, caracterizada pelo conceito de elaboração didática. Sob essa perspectiva, "[...] os conteúdos a se ensinar não se reduzem a saberes científicos transpostos [assim como no conceito de transposição didática], mas refratam também [...] [tal qual propõe Martinand (1986)] as práticas sociais de referência” (PETIT-JEAN, 2008, p. 103). Com base nisso, concordamos com Halté (2008) e Petit-Jean (2008) na argumentação em favor da expansão do conceito de transposição didática, de modo que os três polos do triângulo didático - saber, aluno e professor - sejam, efetivamente, consolidados no espaço escolar, processo implicado na constituição efetiva de uma comunidade de prática (WENGER, 1998), de maneira que ocorra, tal qual propõe Street (2003), uma hibridização das práticas de letramento locais e globais.

\section{Particularização dos procedimentos metodológicos}

Para a presente pesquisa, elaboramos um processo de geração de dados e delineamos diretrizes para a análise desses mesmos dados objetivando a busca de elementos para responder às questôes de pesquisa, as quais vale retomar aqui: Como se caracterizam práticas e eventos de letramento subjacentes/presentes às/nas relaçôes intersubjetivas que crianças de comunidades socioeconomicamente desprivilegiadas e de baixo nivel de escolarizaçāo estabelecem na escola? Os artefatos inseridos no espaço escolar instituem eventos de letramento, de modo que medeiem a instituiçãa das relaçôes interpessoais? 
Para tanto, o estudo que constituiu este artigo caracteriza-se como pesquisa qualitativa, de cunho etnográfico, tematizando o fenômeno do letramento. A instituição escolhida para tal estudo foi uma escola de Educação Básica, que funciona em um bairro desprivilegiado socioeconomicamente localizado em Florianópolis (SC), na qual são desenvolvidas atividades com alunos de Educação Fundamental e Educação de Jovens e Adultos. Nesta pesquisa, trabalhei com um grupo de alunos entre o $4^{\circ}$ e o $5^{\circ}$ ano; também participaram da pesquisa alguns funcionários da escola, tais como coordenadora, bibliotecária estagiária e professores.

Buscar respostas às questões de pesquisa registradas neste artigo, fazendoo sob uma perspectiva qualitativa de cunho etnográfico, implica abrir mão de categorias definidas a priori, dada a natureza do processo por meio do qual o estudo se delineia. Isso não impede, no entanto, que haja elementos norteadores do processo de geração de dados, com ancoragem teórica específica, caminho que optamos seguir. Assim, este estudo foi pautado em teorizações de Hamilton (2000b) acerca das práticas e eventos de letramento. O processo que envolveu observação, notas de campo, pesquisa documental e entrevista teve como foco os elementos visíveis nos eventos de letramento, tais como participantes, ambientes, artefatos e atividades, e os constituintes não visíveis das práticas de letramento, tais como participantes ocultos, dominio, recursos e rotinas.

No entendimento de Hamilton (2000b, p. 17), os participantes correspondem a pessoas que podem ser vistas interagindo com textos escritos. Desse modo, focalizamos como os participantes de pesquisa se apropriam da escrita e as circunstâncias físicas imediatas nas quais a interação se dá, ou seja, em que ambiente essa interação acontece. A autora ressalta, no entanto, que, em determinados situaçôes, como, por exemplo, grande aglomerado de pessoas, é problemático discernir quais indivíduos estão participando efetivamente dos eventos de letramento.

Já os participantes ocultos, segundo Hamilton (2000b, p.17), correspondem a outras pessoas ou grupos de pessoas envolvidas em relações sociais de produção, interpretação, circulação e na regulação de textos escritos; quanto ao domínio das práticas nas quais o evento acontece, particularizá-lo implica levar em conta os sentidos e os propósitos sociais; os recursos, por sua vez, remetem a aspectos trazidos para as práticas de letramento, tais como compreensões, modos de pensar, sentimentos; por fim, importa mencionar as rotinas, que consistem em regras de apropriação, ou seja, quem pode ou não pode se engajar em atividades particulares (HAMILTON, 2000b, p. 17). Mantendo, ainda, como diretrizes norteadoras, os elementos propostos por 
Hamilton (2000b) já mencionados, lançamos mão da observação como instrumento de geração de dados.

Importa registrar que nossa vivência na escola se deu ao longo de seis meses de estudo, com experiências que incluíram interaçōes individualizadas e acompanhamento das atividades em que os participantes estavam inseridos, dentre eles aulas de diferentes disciplinas e idas ao auditório, refeitório e demais locais do ambiente escolar. Importa registrar nossa condição de outsider (KRAMSCH, 1998) para a realização da pesquisa, uma vez que, no estudo, entramos em contato direto com a comunidade escolar, entretanto não nos integramos efetivamente à vida comunitária, ou seja, não convivemos ali a partir da perspectiva de membro. Todas as observaçōes, conversas informais, interpretaçōes e impressōes foram registradas em um diário individual; essas notas transformaram-se em vinhetas narrativas.

Paralelamente aos processos de observação, produção de notas de campo e seleção dos participantes, empreendemos pesquisa documental (MARCONI; LAKATOS, 2007, p. 176) naqueles espaços em que estivemos inseridos. Pesquisamos, no espaço escolar, registros das avaliações descritivas dos alunos participantes de pesquisa, projeto pedagógico da escola, materiais didáticos utilizados, cadernos dos alunos e afins, documentos atinentes à biblioteca, fichas de empréstimo de livros e de materiais escritos similares encontrados na escola, em espaços como salas de aula, corredores, murais e biblioteca.

Lançamos mão, também, de entrevistas caracterizadas como combinações entre perguntas abertas e fechadas; o recurso utilizado para a documentação dos dados foram gravações, posteriormente transcritas; a entrevista foi esboçada a partir de alguns tópicos, delineados a partir dos estudos de Hamilton (2000b). Assim, empreendemos um processo de pesquisa que viabilizou a construção de respostas à problemática que moveu a realização este estudo.

\section{Usos da escrita na escola e (in)sensibilidades aos letramentos locais}

Ao conceber as práticas de letramento como formas gerais de cultura, compreendemos que tais práticas constituem vivências que ancoram os usos da escrita por meio das quais os indivíduos interagem durante suas vidas. Com base nisso, focalizaremos neste estudo a/o possível proximidade/afastamento entre a escola e comunidade, os eventos de letramento no cotidiano escolar e as ações docentes na ressignificação (ou não) das práticas de letramento dos alunos inseridos na escola objeto de estudo deste artigo. 
Em se tratando da escola objeto desta pesquisa, no entanto, parece-nos que a origem das ações teve como âncora não as práticas situadas a que fazemos alusão aqui, mas uma iniciativa europeia exitosa: a conhecida Escola da Ponte. A organização do projeto do contexto com que trabalhamos se deu na tentativa de se assemelhar a tal escola, situada na Vila das Aves, cidade do Porto, em Portugal, uma instituição que busca empreender um distanciamento em relação à escola tida como tradicional. Entendemos que o referencial europeu de excelência eleito pela escola objeto de nosso estudo sem dúvida constitui uma experiência educacional bem-sucedida. Os estudos do letramento, no entanto, fazem-nos conceber a origem do processo educacional no que respeita à escrita como inextrincavelmente vinculada à natureza situada dos usos dessa modalidade da língua por parte de alunos tomados em sua inserção social e histórica (STREET, 2003a).

Desse modo, em nosso entendimento, para que a escola objeto desta pesquisa empreenda de maneira satisfatória um processo dessa natureza construir um projeto pedagógico ancorando-se em uma experiência externa bem-sucedida -, com base nos estudos do letramento, é necessário que os professores sejam sensíveis às práticas de letramento que têm lugar na comunidade, para atuarem, tal qual quer Kleiman (2006), como agentes de letramento nessa mesma comunidade. A geração de dados sinalizou para um desconhecimento em relação à natureza situada dos usos da escrita na comunidade da qual a escola é parte, do que o excerto a seguir é exemplo:

(1) Os professores não conhecem a comunidade em que as crianças vivem, não sabem onde as crianças vivem e muitos nem querem conhecer. Seria muito interessante se nós pudéssemos fazer uma reunião pelo menos uma vez por mês para pesquisar as particularidades da comunidade, porque assim nós poderíamos fazer um trabalho bem interessante, ressignificando os conhecimentos dos alunos. Infelizmente, a escola tem um ótimo Projeto Político-Pedagógico, mas acho que alguns professores nem têm cópia. (Coordenadora pedagógica. Entrevista realizada em 14 de outubro de 2010.)

A adjetivação otimal para caracterizar o projeto pedagógico parece-nos estar assentada na excelência da experiência europeia da qual o projeto derivou, e não exatamente na fecundidade desse projeto como instrumento para a promoção de mudanças naquele ambiente específico. Se nossa análise procede, o projeto "é ótimo" porque corresponde a uma experiência amplamente exitosa; no entanto, no lócus em que se instala, esse caráter otimal está sob suspeição, porque agir à luz do projeto implica sentir-se parte dele, e isso, na essência, requer conhecê-lo intimamente. 
Esse excerto de entrevista com a coordenadora pedagógica materializa a percepção que marcou nossas vivências na escola: a pouca proximidade entre os agentes escolares e os familiares dos alunos. Em nosso entendimento, um dos grandes desafios diz respeito a tomar as práticas educativas sob a perspectiva do modelo ideológico de letramento (STREET, 1984). Vinhetas narrativas que capturam cenas que vivenciamos naquele espaço e interações com professores e funcionários da escola sugerem serem substantivos os desafios para que tal escola promova uma ressignificação das práticas de letramento das crianças, sobretudo em razão de os professores desconhecerem tais práticas da comunidade na qual as crianças estão inseridas:

(2) Não conheço nada da comunidade. Eles até comentam o que teve em casa. Ontem um menino chegou dizendo que teve tiroteio, mas de material escrito eles não falam nada. Nas reuniōes a gente não fala nada sobre a comunidade. Não sei nada sobre esse lugar. (Professora de Português. Entrevista realizada em 24 de setembro de 2010.)

Como já foi mencionado, a instituição escolar, de modo geral e em tese, age historicamente a partir de uma concepção vinculada ao modelo autônomo de letramento (STREET, 1984), o que implica o favorecimento de crianças provenientes de espaços em que os usos da escrita se dão de forma naturalizada, ao passo que em ambientações em que tais usos não são prevalecentes - como na comunidade objeto deste estudo - esse processo acontece artificialmente, $\mathrm{e}$ não como um processo cultural, tal como propõe Gee (2004). Diretores, professores e demais funcionários da escola, em nosso entendimento, devem ser sensíveis aos letramentos vernaculares (ROJO, 2009), de modo que, a partir da lógica subjacente a esses letramentos, seja possível ampliar as práticas de letramento dos alunos, na busca de uma aproximação maior com os letramentos dominantes (ROJO, 2009) que têm lugar na escola. Para tanto, compreendemos que um dos meios possíveis para esse fim consista na elaboração de Projetos Político-Pedagógicos em cuja constituição sejam contempladas as vozes da comunidade escolar. A participação de professores nessa elaboração, no entanto, deveria ser indispensável, já que eles interagem diretamente com os alunos, o que implica conhecer minimamente a comunidade e os usos da escrita que se processam ali. De acordo com a secretária da escola,

(3) Esse projeto tinha tudo para dar certo, mas fica difícil porque os professores são contratados por concurso público só que a maioria dos professores são substitutos. Por isso não há uma continuidade desse professor, tanto para a continuação do professor e dos próprios alunos que se acostumam com 
o professor. E depois muda de professor no próximo ano. Se fosse algo mais fixo, efetivo, seria mais interessante. Sem contar os professores que não se adaptam ao projeto e desistem na metade do ano. (Secretária da escola. Entrevista realizada em 4 de novembro de 2010.)

Esse excerto de entrevista evidencia uma questão central neste estudo: a ausência de um pertencimento efetivo por parte dos professores à escola, 0 que inviabiliza a construção de uma identidade no grupo, ou seja, a construção de uma comunidade de prática (WENGER, 1998). À luz da compreensão de Wenger (1998), é indispensável, no espaço escolar, o engajamento de professores e alunos em atividades significativas cujo processo não consista apenas em aprendizagem de conteúdos determinados aprioristicamente, mas num processo de construção de interesses mútuos acerca de tais atividades. Sob esse entendimento, tal processo agasalha uma questão de pertencimento e de construção de uma identidade tanto por parte dos professores quanto por parte dos alunos. Ao que parece, no entanto, macroprocessos de gestão da instituição escolar objeto deste estudo, assim como de tantas outras escolas brasileiras, tendem a inviabilizar que professores realizem um trabalho significativo, já que sua condição de admissão em caráter temporário lhes impossibilita constituírem-se efetivamente como membros da comunidade de prática, nesse caso, a comunidade escolar.

Já no que respeita aos eventos de letramento do cotidiano escolar, o espaço parece organizar-se mais centralmente na oralidade. Mesmo na biblioteca, território historicamente reservado à modalidade escrita e no qual a oralidade precisa ser silenciada, não prevalecem eventos de letramento efetivos. Tal como tende a se dar em boa parte das instituiçôes escolares em nível nacional (ABREU, 2003), observamos que a biblioteca não significa efetivamente para grande parte das crianças, uma vez que não vivenciamos o engajamento delas em eventos de letramento que poderiam ter lugar nesse espaço. Ao que parece, frequentar a biblioteca não constitui uma prática recorrente dos alunos da instituição.

(4) Os alunos que costumam vir na biblioteca são os que estudam até a terceira série, que a professora traz. Os que já passaram dessa fase não costumam frequentar, mas alguns ainda vêm. É uma pena que muitos param de vir, porque a leitura na vida de uma criança é extremamente importante, ainda mais essas crianças que não têm o hábito de leitura em casa. (Estagiária da biblioteca da escola. Entrevista realizada em 12 de agosto de 2010.) 
No caso em estudo, os artefatos, que encontramos na biblioteca e que poderiam instituir eventos de letramento, parecem estar em estado de letra morta, em uma ambientação mantida muito mais pela tradição do que propriamente pelas demandas do cotidiano escolar. Encontramos, na entrada da biblioteca, um pequeno cartaz nomeando o espaço, o que evidencia razōes dessa nossa inferência: a nomeação escrita "Biblioteca" parece atender à tradição escolar de afixação de cartazes, não constituindo uma informação relevante nas relações interpessoais, porque, ao enxergar o cartaz, as crianças já estão dentro do espaço que sabem ser a biblioteca; logo, não se trata da escrita organizando a mobilidade espacial escolar, mas servindo ao comportamento escolarizado de ilustração das paredes com cartazes diversos. Em nossa compreensão, para que os artefatos inseridos na biblioteca instituam eventos de letramento, é necessário que esses mesmos artefatos sejam significativos para os sujeitos que estão inseridos na instituição, de modo que medeiem as interaçôes entre esses mesmos sujeitos.

Fora da biblioteca, os alunos estão expostos a materiais escritos rarefeitos, contrariando nossa percepção típica do espaço escolar. $\mathrm{Na}$ sala de aula da classe objeto de nossa açãao de pesquisa, as paredes expõem um pequeno cartaz sobre o sistema solar. Essa condiçăo, mais uma vez, parece ilustrar um comportamento clássico escolar de afixação de cartazes nas paredes. Ainda em se tratando dessa discussão, no canto da sala de aula, há um espaço destinado ao "cantinho dos recados", que, em tese, deveria ser um espaço amplamente interativo; nesse ambiente, encontramos, ao longo de nossas vivências, os horários das disciplinas e o espelho de classe. Identificamos, mais uma vez aqui, um artefato que não institui relaçôes interpessoais, uma vez que, em nossas vivências, observamos que os alunos não se assumem como participantes de um evento por meio desse "cantinho de recado". Ainda no que respeita aos usos da escrita encontrados na escola, observamos que a sala de aula da classe objeto de estudo dispóe de uma pequena estante com vários livros. Encontramos esse material razoavelmente bem organizado, o que sugere que possivelmente os alunos não manuseiem os livros com muita frequência. A sala também dispõe de dois computadores, mas, devido à posição em que estão colocados, não parecem ser usados pelos alunos; ao longo de nossa vivência na escola, os computadores se mantiveram desse modo. Fomos informados de que estáo quebrados desde o início do ano, o que parece ilustrar um comportamento desolador: os computadores estão ali, mas não servem para seu sentido e propósitos sociais.

Outra questão importante, em se tratando de nosso estudo, diz respeito à comunicação entre escola e comunidade por meio da escrita. No espaço 
escolar, não constatamos uma comunicação efetiva entre escola e família por meio de bilhetes ou agendas. Segundo a secretária da escola:

(5) As crianças ainda não sabem da importância de um bilhete enviado pela escola e não mostram, ou mesmo muitos pais são analfabetos, não têm a apropriação da língua padrão culta ou não entendem mesmo, apesar de a gente tentar fazer o mais simples possível. Tem uns que ligam e perguntam "mas afinal tem aula ou não tem...". Às vezes, nem vale muito a pena enviar. (Secretaria da escola. Entrevista realizada em 12 de agosto de 2010.)

Ao que parece, na escola, não há valoração da interação com alunos e familiares por meio da escrita, o que, em nosso entendimento, evidencia os recursos (HAMILTON, 2000b) trazidos para as práticas de letramento, tais como compreensões, modos de pensar e habilidades, assim como os domínios dessas mesmas práticas, ou seja, o sentido e propósito social que constitui um evento de letramento dessa natureza. Eis aqui uma questão central: as práticas de letramento dos pais não sustentam eventos de letramento como a interação por meio de bilhetes ou agendas, por isso telefonam, prevalecendo a oralidade.

Já no que diz respeito aos usos da escrita inseridos nas diferentes disciplinas do currículo, importa registrar que, no projeto sob o qual se pauta a ação escolar, além das disciplinas que constituem o currículo comum, postulado pela Lei de Diretrizes e Bases da Educação (1996), a escola mantém outras disciplinas, tais como aulas de Música, de Teatro, de Meteorologia, de Projetos de Trabalho e de Tutoria.

Desse modo, em se tratando dos usos da escrita nas disciplinas oferecidas na escola, não encontramos, durante nossa vivência, grande variedade de eventos de letramento; em muitas dessas disciplinas, a presença da escrita era praticamente inexistente. Se retomarmos as considerações teóricas acerca do pensamento vygotskyano (VIGOTSKI, 1998), parece flagrante que, se a escola não agir na Zona de Desenvolvimento Imediato da criança, não haverá possibilidade de apropriação de novos saberes nas relações intersubjetivas, e, como consequência, tais relaçôes intersubjetivas que constituem a razão de existir da escola tornamse inócuas. Essa ausência da escrita que vivenciamos nas aulas, muitas vezes motivada pelas condiçôes de a(na)lfabetismo dos alunos, ${ }^{1}$ parece constituir uma

\footnotetext{
${ }^{1} \mathrm{Na}$ classe objeto deste estudo, há quem não saiba ler em letra cursiva, domínio que seria esperado em razão da seriação escolar em que os alunos se encontram: $4^{\circ}$ e $5^{\circ}$ anos.
} 
adaptação à sua Zona de Desenvolvimento Real - como eles têm dificuldades para ler e escrever, são submetidos a aulas em que a oralidade tem lugar de destaque. Não havendo um processo de elaboração didática (HALTÉ, 2008) construído a partir da Zona de Desenvolvimento Imediato (VIGOSTKI, 1998) das crianças, não haverá hibridização de suas práticas de letramento com as práticas de letramento dominantes, tal qual sugere Street (2003a).

Em algumas disciplinas, a escrita apareceu de forma recorrente, sem, entretanto, grandes variedades de eventos de letramento, já que, em nossas vivências, encontramos apenas o uso de livros didáticos. Como mencionamos por ocasião da fundamentação teórica, Petit-Jean (2008) compreende, com base em Chevallard (1985), que a transposição didática assinala a passagem do saber científico para o saber ensinado. Sob esse olhar, um dos grandes problemas do conceito diz respeito ao fato de um professor seguir um modelo, determinado a priori, o que remete, mais uma vez, às teorizaçôes de Street (1984) acerca do modelo autônomo de letramento. A vinheta narrativa a seguir, fruto de observação de aula de Teatro, sinaliza para essa condição:

(a) O professor entra na sala, pega um livro de mitos e lê o título de alguns mitos contidos no livro para os alunos escolherem com o qual gostariam de trabalhar. Os alunos não são informados de que se trata de "mito" e desconhecem nome da obra e autor. As crianças não manuseiam o material; observam-no de longe. Depois de uma votação em que não percebemos um envolvimento maior por parte dos alunos, o mito escolhido foi "Perseu e a cabeça da Medusa". Então, o professor lê a história escolhida dado que a ele compete o acesso ao material escrito, uma vez que os alunos não dispōem de uma cópia xerografada. A turma mantém um comportamento de alheamento. (Diário de campo, 11 de maio de 2010. Nota n. 2. Aula de Teatro.)

O professor da disciplina, na aula em questão, comprometido em trabalhar especificamente com mitos, transpõe - o saber científico - para sua prática em sala de aula atividades provenientes da graduação e dos cursos teatrais, ou seja, de um ambiente (HAMILTON, 2000b) distinto do ambiente escolar: a forma como a atividade se desenvolve possivelmente tenha lugar na comunidade de prática (WENGER, 1998) de origem do professor, mas não parece significar na ambientação escolar. Inferimos, a partir de cenas como essas, que esses planejamentos escolares, tal como tende a acontecer historicamente na educação, parecem delineados aprioristicamente, independentemente da configuração dos letramentos locais (STREET, 
2003a). Sob esse entendimento, ao que parece, tais crianças desconhecem determinados gêneros da esfera literária, tal como mitos, e não estão familiarizados com usos da modalidade escrita que têm lugar em determinados espaços. Em nosso entendimento, há, aqui, implicações de comunidades de práticas distintas em relação às ações docentes e discentes, o que remete às rotinas suscitadas nos estudos de Hamilton (2000b), uma vez que, em situações como essas, os alunos parecem ter dificuldades para se engajar nos eventos de letramento propostos. Uma explicação possível é que, como nesses dois casos, tais eventos tenham lugar em esferas da atividade humana muito distintas das esferas nas quais estão habituados a circular e demandem sustentação em práticas de letramento demasiadamente diversas daquelas vivenciadas pelas crianças - eis os letramentos dominantes e a impossibilidade de facultar aos alunos acessos a eles sem considerar os letramentos vernaculares. A vinheta narrativa a seguir ilustra essa condição:

(b) A professora entra na sala e explica o conteúdo que foi copiado no quadro na aula anterior. A aula é ministrada em meio a muito barulho; vários alunos ficam brincando e não prestam atenção às explicaçôes. Depois, a professora registra novos conteúdos no quadro: "pressão atmosférica". Ao que parece, ela segue a sequência do livro didático - os alunos não têm acesso ao livro. Poucos dentre eles copiam; a grande maioria conversa e reclama que tem de copiar matéria do quadro. (Diário de campo, 26 de maio de 2010. Nota n. 16. Aula de Meteorologia.)

Parece legítimo conceber que, em sua grande maioria, as crianças inseridas na classe em que se deu o estudo tomam parte de comunidades de prática nas quais participam de eventos de letramento vernaculares, o que possivelmente explica o estranhamento de tais crianças em relação a esses eventos de letramento dominantes, sugerindo que, no ambiente escolar, tais crianças não se reconhecem como participantes nesse evento de letramento (HAMILTON, 2000b) específico. Sob esse olhar, é possível compreender porque esses alunos inseridos em comunidades de prática de baixo nível de escolarização relutam em aderir a determinadas propostas de interação mediadas pela modalidade escrita no espaço escolar, processos em que, muitas vezes, nós, como educadores, interpelados pelo modelo autônomo de letramento (STREET, 1984), nos deixamos contaminar pela suposição de que, estando inserido na escola, o aluno naturalmente compreenderá os sentidos dos eventos de letramento dominantes que lhes apresentamos, pelo simples fato de que tais 
eventos são parte constitutiva da formação da cultura macrossociológica de que fazem parte como seres humanos ocidentais. Outra vinheta narrativa ilustra essa condição:

(c) A professora chega à sala e diz que esta aula será diferente: "já que vocês já sabem o que é uma fábula, vocês vão produzir uma”. As crianças parecem não gostar da ideia; reclamam, ao longo da aula, da atividade a ser feita. Primeiramente a professora passa um texto no quadro que recapitula o que é uma "fábula". Os alunos demoram para copiar e só começaram a "produzir" a fábula no final da aula. (Diário de campo, 22 de junho de 2010. Nota n. 22. Aula de Língua Portuguesa.)

Essa cena reitera nossa percepção do caráter inócuo da ação escolar no trato com a modalidade escrita: definir o que é uma fábula, no quadro, para depois produzir uma fábula, seguramente constitui um procedimento que existe só e para a escola, distanciando-se substancialmente de tomar a escrita como processo cultural, tal qual suscitado nos estudos de Gee (2004). Por meio das vivências que tivemos na escola e mesmo com a interação com os profissionais, inferimos que os professores da instituição, tal qual se processa em muitos outros contextos, estão perpassados pela concepção universalista da modalidade escrita, proposta pelo modelo autônomo de letramento (STREET, 1984), remetendo à descontextualização das açôes pedagógicas em se tratando da ressignificação dos letramentos locais; em nossas vivências na escola, convivemos com oportunidades efetivas em que os letramentos vernaculares poderiam ter se constituído como pontos de partida para um processo interacional por meio da modalidade escrita, com delineados na vinheta a seguir.

(d) Algumas meninas gostam de fazer anotaçōes em um diário e interagem entre elas com o artefato. Os professores parecem adotar um comportamento prototípico em relação à atividade, recomendando que os diários sejam guardados. Caso contrário, vão para a direção. (Diário de campo, 6 de julho de 2010. Nota n. 23. Aula de Projetos.)

Cabe reiterar que não estamos advogando em favor da compreensão de que as crianças, no espaço escolar, devam realizar atividades em que apenas materiais vernaculares estejam presentes, o que certamente daria suporte às críticas empreendidas por Brandt e Clinton (2002), segundo as quais, ao se enfatizar o letramento local, há um estreitamento das teorizaçóes do conceito de letramento em si. Com base nisso, as observaçôes sugerem, então, em diversos momentos, interessantes oportunidades de hibridizar, dialeticamente, 
os universos global e local, o que, porém, não foi observado nos espaços de interação de que participamos durante o tempo da pesquisa. Possivelmente, a história da Educação, tal qual tem se construído, não nos tenha educado para planejarmos nossas ações didático-pedagógicas à luz dessa necessária movimentação dialética entre o local e o global (STREET, 2003a). Há, aqui, uma questão central em nosso estudo: de que maneira os professores da instituição podem promover essa hibridização se, ao que parece, eles mesmos não se apropriaram de aspectos do plano global? De acordo com a coordenadora pedagógica:

(6) O grande problema dos professores aqui, e acredito que em outras escolas também, é que os professores não ressignificam as práticas da comunidade e dos alunos. Não tem como eles promoverem uma união entre o que é local e o que é dominante, porque os professores não sabem ao menos o que é dominante. Como que eles vão ampliar os conhecimentos desses alunos se os próprios conhecimentos deles não foram ampliados? Eles sabem, pelo menos deveriam saber, o que aprenderam na universidade, mas daí a conseguir fazer com que isso vire prática pedagógica, é outra coisa. (Coordenadora pedagógica. Entrevista realizada em 14 de outubro de 2010.)

A despeito dessa dificuldade, convivemos com planejamentos escolares que acenam para maior sensibilidade aos letramentos locais da comunidade. Em uma das aulas de Geografia, a professora distribuiu o livro Uma aventura em Santa Catarina às crianças. Pelo que pudemos perceber, os alunos já tiveram contato com essa obra em outras ocasiôes. No início, somente alguns alunos leram o livro e discutiram entre si. O interessante é que, quando as crianças que não estavam participando da atividade perceberam do que se tratava a discussão, começaram a ler também e entraram na conversa. De posse do material, percebemos que o livro traz várias passagens com explicaçōes de locais históricos da Ilha de Santa Catarina, lugares esses que várias dessas crianças já frequentaram em algum momento de suas vidas. Apesar de tal interação mediada pela obra constituir um evento vinculado aos letramentos dominantes, pertinente ao universo global, tal qual propõe Street (2003a), o tema materializado na obra é amplamente conhecido do plano local, do que possivelmente tenha decorrido, em boa medida, o fato de as crianças se reconhecerem naquele artefato e, consequentemente, engajarem-se naquele evento de letramento. Em conversas informais com essa profissional, registramos sua preocupação com a comunidade e com a inserção dessa mesma comunidade no universo global no que respeita ao acesso aos letramentos dominantes: 
(7) Eu não entro na comunidade porque tenho um pouco de medo da violência, mas sempre pergunto aos alunos onde eles moram, o que fazem, o que tem na comunidade. Acho importante nós professores conhecermos o contexto sócio-histórico dos estudantes para o trabalho ser mais produtivo. As aulas só têm sentido para eles quando consideramos o conhecimento que eles trazem para a escola. (Professora de Geografia. Entrevista realizada em 17 de maio de 2010.)

Esse excerto de entrevista sugere que a professora reconhece a necessidade de conhecer o espaço em que os alunos se inserem, mas não estabelece relações entre esse desconhecimento e o interesse deles. Em nossa compreensão, as práticas no espaço escolar devem ser caracterizadas pelo envolvimento mútuo e conjunto no qual o engajamento dos alunos em atividades nesses espaços sejam significativos e em torno de um objetivo comum, como parece acontecer, ainda que embrionariamente, nas aulas de Geografia, por exemplo. Sob esse entendimento, para que a escola se constitua como tal e promova a hibridização dos planos local e global, faz-se necessário que os alunos estejam inseridos em um círculo de pertencimento e participação, uma vez que é em comunidades de prática (WENGER, 1998) que as relações são construídas.

\section{Considerações finais}

Este artigo, focado nos estudos do letramento, buscou descrever, com base em teorizações de Hamilton (2000b), práticas e eventos de letramento vivenciados por um grupo de crianças na escola, residentes em um bairro de vulnerabilidade social no município de Florianópolis (SC). Os resultados evidenciam que a hipotetizada divergência entre práticas de letramento que caracterizam o espaço escolar e práticas de letramento que caracterizam a ambientação familiar de tais alunos não parece ser o foco efetivo implicado na não ressignificação das representações das crianças sobre os usos da modalidade escrita da língua na sociedade contemporânea. Parece haver, na verdade, uma flagrante ausência de escrita na ambientação escolar e nas aulas dessa classe, muitas vezes motivada pelas condições de a(na)lfabetismo dos alunos e, possivelmente, na origem, por uma tácita naturalização da não aprendizagem que tende a caracterizar espaços de vulnerabilidade social como esse.

À luz das teorizações de Vygotsky (1998), parece evidente que, se a escola não agir na Zona de Desenvolvimento Imediato da criança, e, como consequência, os professores não se assumirem como agentes de letramento (KLEIMAN, 2006), não haverá possibilidade de apropriação de novos saberes 
nas relações intersubjetivas. Não havendo um processo de elaboração didática (HALTÉ, 2008) construído a partir da Zona de Desenvolvimento Imediato (VIGOSTKI, 1998) das crianças, não haverá hibridização entre suas práticas de letramento e as práticas de letramento dominantes, tal qual sugere Street (2003a). Vivências na escola sinalizam, ainda, que, dentre vários aspectos, tal processo de hibridização está inviabilizado também em razão das dificuldades docentes no que diz respeito à efetiva apropriação dos letramentos dominantes.

\section{Referências}

ABREU, M. Os números da cultura. In: RIBEIRO, V. M. (Org.). Letramento no Brasil: reflexões a partir do INAF 2001. 2. ed. São Paulo: Global, 2003. p. 47-64. BALTAR, M. A. R. Mídia, escola, agentes de letramento e gêneros textuais. In: SERRANI, S. (Org.). Letramento, discurso e trabalho docente. Vinhedo: Horizonte, 2010. p. 211-227.

BARTON, D. Literacy: an introduction to the ecology of written language. Cambridge, MA: Blackwell, 1994.

BARTON, D.; HAMILTON, M. Local literacies. London; New York: Routledge, 1998.

BARTON, D.; HAMILTON, M.; IVANIC, R. Situated literacies. London: Routledge, 2000.

BRANDT, D.; CLINTON, K. Limits of the local: expanding perspectives on literacy as a social practice. Journal of Literacy Research, v. 34, n. 3, p. 337-356, 2002. GEE, P. J. Situated language and learning: a critique of traditional schooling. London: Routledge, 2004.

CHEVALLARD, Y. La transposition didactique. Grenoble: La Pensée Sauvage, 1985.

HALTÉ, J. F. O espaço didático e a transposição. Fórum Linguístico, Florianópolis, v. 5, n. 2, p. 117-139, jul.-dez. 2008.

HAMILTON, M. Sustainable literacies and the ecology of lifelong learning. In: KEYNES, M. (Org.). Working papers of the global colloquium on supporting lifelong learning. Buckinghamshire, UK: Open University, 2000a. Disponível em: <http://www.open.ac.uk/lifelong-learning>. Acesso em: 10 maio 2010.

HAMILTON, M. Expanding the new literacy studies: using photographs to explore literacy as social practice. In: BARTON, D.; HAMILTON, M.; IVANIC, R. (Org.). Situated literacies. London: Routledge, 2000b. p. 16-34. 
HEATH, S. B. What no bedtime story means: narrative skills at home and school. In: DURANTI, A. (Org.). Linguistic anthropology: a reader. Oxford: Blackwell, 2001. p. 318-342.

KLEIMAN, A. Processos identitários na formação profissional: o professor como agente de letramento. In: CORREIA, M. L. G.; KOCH, F. (Org.). Ensino de lingua: representação e letramento. Campinas: Mercado de Letras, 2006. p. 75-91.

KLEIMAN, A. Professores e agentes de letramento: identidade e posicionamento social. Revista Filologia e Linguistica Portuguesa, n. 8, p.409-424, 2007.

KRAMSCH, C. Language and culture. Oxford; New York: Oxford University Press, 1998.

MARCONI, M. A; LAKATOS, E. M. Fundamentos de metodologia científica. São Paulo: Atlas, 2007.

MARTINAND, J. L. Connaître et transformer la matière. Bern: Peter Lang, 1986. OLIVEIRA, M. S. Gêneros textuais e letramento. Revista Brasileira de Linguistica Aplicada, Belo Horizonte, v. 10, n. 2, p. 325-345, 2010.

PETIT-JEAN, A. Importância e limites da noção de transposição didática para o ensino do francês. Fórum Linguístico, Florianópolis, v. 5, n. 2, p. 83-116, jul.dez. 2008.

ROJO, R. Letramentos múltiplos, escola e inclusão social. São Paulo: Parábola, 2009.

STREET, B. Literacy in theory and practice. Cambridge, MA: Cambridge University Press, 1984.

STREET, B. Abordagens alternativas ao letramento e desenvolvimento. In: TELECONFERENNCIA UNESCO BRASIL SOBRE LETRAMENTO E DIVERSIDADE, out. 2003a. Comunicação oral.

STREET, B. What's "new" in new literacy studies? Critical approaches to literacy in theory and practice. Current Issues in Comparative Education, Columbia, v. 5, n. 2, p. 77-99, 2003b.

STREET, B.; LEFSTEIN, A. Literacy: an advanced resource book. London; New York: Routledge, 2007.

VYGOTSKY, L. A formação social da mente. Tradução de José Cipolla Neto, Luis Silveira Menna Barreto e Solange Castro Afeche. 6. ed. São Paulo: Martins Fontes, 1998.

WENGER, E. Communities of practice: learning, meaning and identity. Cambridge, MA: Cambridge University Press, 1998.

Recebido em 15/03/2012. Aprovado em 20/08/2012. 